\title{
Fatal Disseminated Intravascular Coagulopathy in Covid-19: A Small Case Series
}

\author{
Samia Kazmi, $\mathrm{MBBS}^{1}$ \\ ${ }^{1}$ Department of Internal Medicine, The Indus Hospital, Karachi, \\ Pakistan \\ 2 Department of Infectious Disease, The Indus Hospital, Karachi, \\ Pakistan
}

Semin Thromb Hemost 2021;47:427-430.
Samreen Sarfaraz, MBBS, MRCP, FRCP2

\begin{abstract}
Address for correspondence Samia Kazmi, MBBS, Department of Internal Medicine, The Indus Hospital, Plot C-76, Sector 31/5, Opposite Darussalam Society, Korangi Crossing, Karachi, 75190, Pakistan (e-mail: samia.kazmi@tih.org.pk).
\end{abstract}

Coronavirus disease 2019 (COVID-19) has proven to be a multifaceted disease in terms of presentation and varied complications, ranging from almost asymptomatic to death, thus setting new challenges for the medical community worldwide. Coagulopathy in association with thrombotic complications and perhaps even disseminated intravascular coagulation (DIC) have become the hallmark of severe acute respiratory syndrome coronavirus 2 infections. Klok et al evaluated a cohort of 184 intensive care unit patients, reporting a cumulative incidence of thrombotic complications as high as $31 \%$, with pulmonary thrombosis displaying the highest occurrence despite standard thromboprophylaxis. ${ }^{1}$ Related studies have also described a high prevalence of thrombotic complications in COVID-19 patients, thus suggesting that intensification of thromboprophylaxis may be considered in patient management. ${ }^{2-6}$

The ultimate outcome of coagulopathy and the potential onset of DIC, primarily a type of prothrombotic variant, have posed many management challenges in COVID-19 patients. Several studies have predicted poor outcomes in association with markedly high levels of D-dimer, a fibrin degradation product (FDP), thus validating its prognostic role in disease management. 7

The current guidance with regard to prevention of thrombosis and management of coagulopathy and DIC recommends pharmacological thromboprophylaxis be given to all immobilized and severely ill patients with COVID-19 unless otherwise contraindicated. ${ }^{8}$

We wish to report on four cases of DIC, encountered out of 28 COVID-19 patients admitted in our facility at the time: two cases of thrombotic complications with superimposed DIC and two of overt DIC, despite adequate thromboprophylaxis.

Case 1: 51-year-old male, physician, suffering from hypertension and diabetes mellitus, was admitted with a 10day history of cough and flu-like symptoms. Vital signs on presentation were temperature $(\mathrm{T}) 37^{\circ} \mathrm{C}$, heart rate (HR) 130 beats per minute (bpm), blood pressure (BP) $167 / 93 \mathrm{~mm} \mathrm{Hg}$, respiratory rate (RR) 45 per minute, and oxygen saturation $\left(\mathrm{SpO}_{2}\right)$ of $70 \%$ on room air. Clinical characteristics and laboratory parameters on presentation are summarized in -Table 1. The polymerase chain reaction (PCR) assay for COVID-19 was positive. Due to very high D-dimer levels (> $15,000 \mu \mathrm{g} / \mathrm{L}$, fibrinogen equivalent units, low molecular weight heparin (LMWH) was initiated at prophylactic dosage of $40 \mathrm{mg}$ once daily subcutaneously from the first hospital day (HD). Due to hypoxemic respiratory failure, the patient was ventilated starting from the second $\mathrm{HD}$, when his $\mathrm{PaO}_{2} /$ $\mathrm{FiO}_{2}$ ratio was 65.5. On HD 10, he developed new-onset rightsided hemiplegia and ptosis. Computed tomography (CT) head plain revealed acute ischemic infarct in the left middle cerebral artery territory, involving the frontoparietal region (-Fig. 1). Aspirin and high-dose statins were started. CT pulmonary angiogram performed on that same day showed bilateral pulmonary artery thrombosis (-Fig. 2). However, due to the acute stroke, full dose of anticoagulation was withheld initially and started 48 hours later after reevaluation with neuroimaging, to rule out extension or bleed within the infarct. Venous Doppler ultrasonography of lower extremities excluded deep venous thrombosis and echocardiography was normal, with no arrhythmias noted on electrocardiogram. Subsequently, he was administered an unfractionated heparin (UFH) infusion at 18 units $/ \mathrm{kg} / \mathrm{h}$, with strict activated partial thromboplastin time (aPTT) monitoring; the UFH was later withheld after 12 hours as he developed melena. He was managed with blood products, including fresh frozen plasma (FFP). He continued to exhibit clinical worsening, with derangements in coagulation profile by HD 14. Prothrombin time/international normalized ratio (PT/INR) was 26.1 seconds/2.49 and based on the International Society on Thrombosis and Haemostasis (ISTH) score of 6 , a diagnosis of overt DIC was made. He continued to deteriorate, eventually developing multiorgan failure (MOF) requiring single session of hemodialysis; superimposed published online December 17, 2020
Issue Theme Maintaining Hemostasis and Preventing Thrombosis in COVID-19 -Part II; Guest Editors: Emmanuel J. Favaloro, PhD, FFSc (RCPA) and Giuseppe Lippi, MD. (c) 2020. Thieme. All rights reserved. Thieme Medical Publishers, Inc., 333 Seventh Avenue, 18th Floor, New York, NY 10001, USA
DOI https://doi.org/ 10.1055/s-0040-1716871. ISSN 0094-6176. 


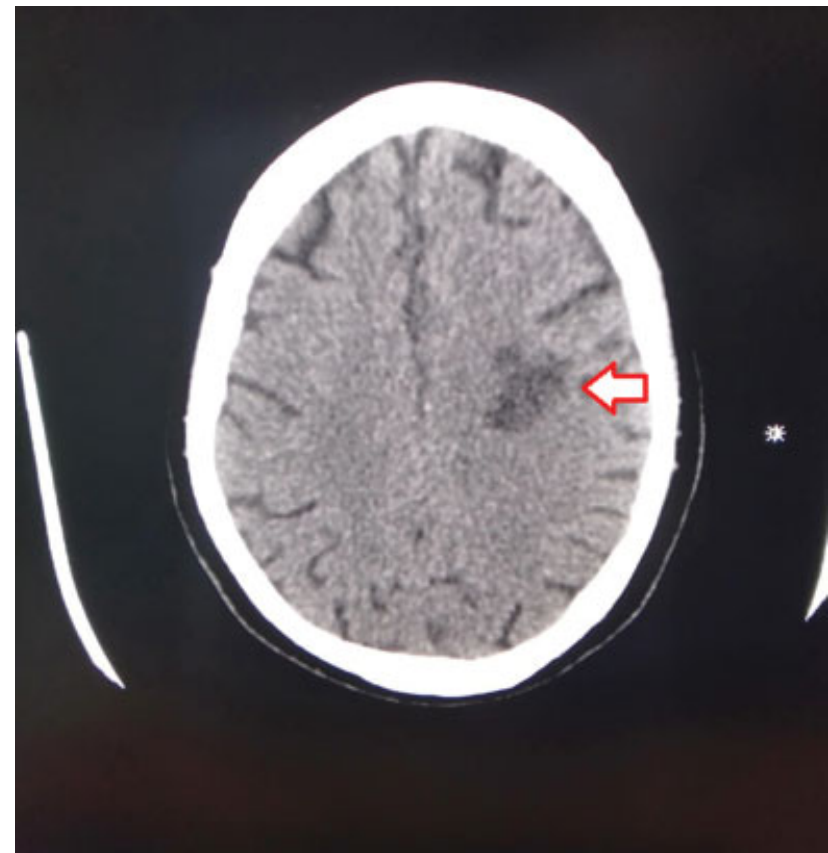

Fig. 1 Computed tomography head plain film demonstrating acute ischemic infarct of the left middle cerebral artery territory (arrowed).

candidemia contributed to his death on the 16th day of admission.

Case 2: 72-year-old male, ex-smoker with no prior comorbidities was admitted with a 4-day history of shortness of breath. His vital signs on presentation were T $37^{\circ} \mathrm{C}$, HR 123 bpm, BP $144 / 64 \mathrm{~mm} \mathrm{Hg}$, RR 25 per minute, and $\mathrm{SpO}_{2}$ of $82 \%$. Chest X-ray showed bilateral infiltrates in the lower zones with a positive PCR assay for COVID-19. Standard thromboprophylaxis with LMWH at $40 \mathrm{mg}$ once daily subcutaneously was initiated. On HD 2, due to worsening oxygenation and a $\mathrm{PaO}_{2} / \mathrm{FiO}_{2}$ ratio of 80 , he was electively intubated and ventilated. On the subsequent day, he developed fever and hypotension. A sample for blood culture and sensitivity was sent and the patient was resuscitated with intravenous fluids and vasopressors due to the possibility of septic shock. On HD 4 , his platelet count dropped to $30 \times 10^{9} / \mathrm{L}$, but no active bleeding was observed; however, LMWH was withheld. The probability of heparin-induced thrombocytopenia was considered low on 4T score. On HD 7, he developed bleeding from endotracheal tube and was transfused with blood products including platelets. On the same day, he developed progressive left thumb cyanosis with impending gangrene at the side where his arterial line was placed. Ultrasound color Doppler revealed thrombus of the left radial and ulnar artery for which anticoagulation with LMWH at $1 \mathrm{mg} / \mathrm{kg}$ every 12 hourly subcutaneously was initiated. He expired on HD 10 due to MOF including acute renal shut down, refractory hypotension, and overt DIC with a total ISTH score of 5 .

Case 3: 38-year male patient with no prior comorbidities was admitted with a diagnosis of COVID-19 pneumonia (-Table 1). Chest X-ray showed ground glass infiltrates with predilection in the lower lung fields. On arrival, he had a $\mathrm{PaO}_{2} / \mathrm{FiO}_{2}$ ratio of less than 100 representing severe

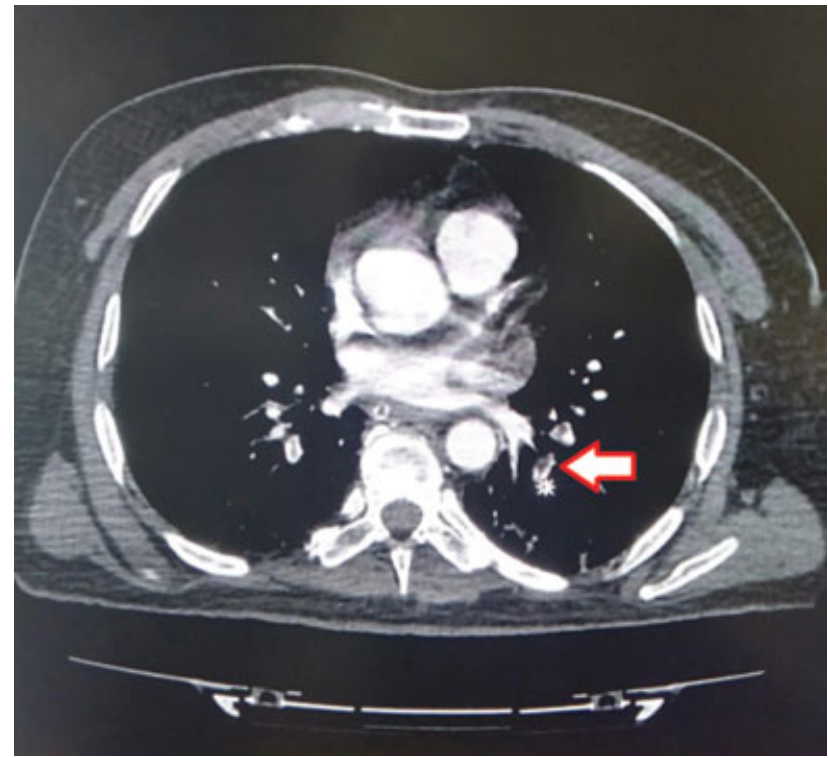

Fig. 2 Computed tomography pulmonary angiography demonstrating bilateral pulmonary artery thrombosis (arrowed).

acute respiratory distress syndrome requiring noninvasive mechanical ventilation. Thromboprophylaxis was commenced with UFH 5,000 units every 12 hours as LMWH was unavailable in stock and was being arranged. Due to ensuing hypoxic respiratory failure, invasive ventilation was initiated on HD 8. On the same day, we observed fluid unresponsive hypotension; therefore, vasopressor support was started. On HD 9, he developed oliguria as a result of acute kidney injury with derangements in coagulation profile resulting in PT/INR of (41.4 seconds/3.94) and aPTT $>120$ seconds. Bleeding complications developed with wide spread purpurae over extremities. An ISTH score of 5 indicated overt DIC, therefore FFPs were transfused. Due to progressive deterioration, and development of overt DIC, the patient expired on HD 12.

Case 4: 65-year-old male with no prior comorbidities with a chest X-ray showing ground glass opacities and a positive PCR assay was diagnosed with COVID-19 pneumonia. He was put on invasive ventilation due to hypoxia on HD 1 and thromboprophylaxis was commenced with UFH 5,000 units every 12 hours subcutaneously. Cardiac arrhythmias developed on $\mathrm{HD} 2$, followed by high $\mathrm{FiO}_{2}$ requirements. On $\mathrm{HD} 3$, PT/INR was 26.9 seconds/2.56 with ISTH score of 5, diagnosis of overt DIC was established. Due to high risk of bleeding, UFH was withheld. On the following day, patient had a cardiac arrest secondary to asystole as a result of rapid clinical deterioration with mild bleeding from endotracheal tube and despite maximal efforts to resuscitate him, he expired on HD 4.

In summary, cases 1 and 2 developed thrombotic complications despite standard thromboprophylaxis, with overt DIC observed in all four cases (median day 5 of admission). The ISTH score assessment was used for diagnosis of DIC and management was performed accordingly, with overt DIC defined as more than or equal to 5 points. D-dimer, ferritin, C-reactive protein (CRP), platelet count, PT/INR, and aPTT 
Fatal Disseminated Intravascular Coagulopathy in Covid-19 Kazmi et al. 429

Table 1 Clinical characteristics and laboratory parameters of five patients at the time of presentation

\begin{tabular}{|c|c|c|c|c|}
\hline Variable & Case 1 & Case 2 & Case 3 & Case 4 \\
\hline Age (y) & 51 & 72 & 38 & 65 \\
\hline Sex & Male & Male & Male & Male \\
\hline Medical history & DM, HTN & None & DM & None \\
\hline Drugs given & $\begin{array}{l}\text { HCQ, methyl } \\
\text { prednisolone, } \\
\text { LMWH/heparin, } \\
\text { tocilizumab }\end{array}$ & $\begin{array}{l}\text { HCQ, methyl } \\
\text { prednisolone, } \\
\text { LMWH, } \\
\text { tocilizumab }\end{array}$ & $\begin{array}{l}\text { HCQ, methyl } \\
\text { prednisolone, } \\
\text { LMWH/heparin, tocili- } \\
\text { zumab, IVIG }\end{array}$ & $\begin{array}{l}\text { HCQ, methyl } \\
\text { prednisolone, } \\
\text { heparin, tocilizumab, IVIG }\end{array}$ \\
\hline $\begin{array}{l}\text { Duration of COVID- } \\
19 \text { symptoms (d) }\end{array}$ & 10 & 4 & 7 & 5 \\
\hline Outcome & Deceased & Deceased & Deceased & Deceased \\
\hline $\begin{array}{l}\text { White cell } \\
\text { count } / \mathrm{mm}^{3}\end{array}$ & 20.7 & 26.5 & 11.4 & 10.3 \\
\hline $\begin{array}{l}\text { Platelet count } \\
\left(\times 10^{9} / \mathrm{L}\right)\end{array}$ & 330 & 151 & 331 & 329 \\
\hline $\begin{array}{l}\text { Prothrombin time } \\
\text { (s)/INR }\end{array}$ & $11.3 / 1.08$ & $14.8 / 1.41$ & $10.3 / 0.98$ & $26.9 / 2.56$ \\
\hline $\begin{array}{l}\text { Activated partial } \\
\text { thromboplastin } \\
\text { time (aPTT) (s) }\end{array}$ & 30.8 & 29 & 18 & 20 \\
\hline CRP (mg/L) & 274 & 139 & 103 & 432 \\
\hline $\begin{array}{l}\text { D-dimer }(\mu \mathrm{g} / \mathrm{L}) \\
\text { (FEU) }\end{array}$ & 12,000 & $>15,000$ & $>15,000$ & 7,230 \\
\hline $\mathrm{LDH}(\mathrm{u} / \mathrm{L})$ & 728 & 427 & 899 & 689 \\
\hline Ferritin (ng/mL) & 2,752 & 414 & 1,105 & $>1,675$ \\
\hline $\begin{array}{l}\text { Worst laboratory } \\
\text { parameter(s) } \\
\text { (value) }\end{array}$ & $\begin{array}{l}\text { D-dimer } \\
\text { Ferritin } \\
\text { PT/INR on day } 14 \\
(26.1 / 2.49)\end{array}$ & $\begin{array}{l}\text { D-dimer } \\
\text { Platelet count on } \\
\text { day } 4(30)\end{array}$ & $\begin{array}{l}\text { D-dimer } \\
\text { PT/INR on day } 9 \\
(41.4 / 3.94) \\
\text { aPTT on day } 9 \\
(>120 \mathrm{~s})\end{array}$ & $\begin{array}{l}\text { D-dimer } \\
\text { PT/INR }(26.9 / 2.56) \text { on day } 3 \\
\text { aPTT }(>120 \mathrm{~s}) \text { on day } 3\end{array}$ \\
\hline $\begin{array}{l}\text { Thromboembolic } \\
\text { event } \\
\text { (occurred on HD) }\end{array}$ & $\begin{array}{l}\text { Left MCA thrombus } \\
\text { (HD 10), bilateral pul- } \\
\text { monary artery throm- } \\
\text { bi (HD 11) }\end{array}$ & $\begin{array}{l}\text { Left radial and ulnar } \\
\text { artery thrombus } \\
\text { (HD 5) }\end{array}$ & $\begin{array}{l}\text { Overt DIC } \\
(\mathrm{HD} 9)\end{array}$ & $\begin{array}{l}\text { Overt DIC } \\
(\text { HD 3) }\end{array}$ \\
\hline $\begin{array}{l}\text { ISTH score for DIC } \\
\text { (calculated on HD) }\end{array}$ & $\begin{array}{l}6 \\
\text { (HD 14) }\end{array}$ & $\begin{array}{l}5 \\
(\mathrm{HD} 4)\end{array}$ & $\begin{array}{l}5 \\
\text { (HD 9) }\end{array}$ & $\begin{array}{l}5 \\
(\mathrm{HD} 3)\end{array}$ \\
\hline
\end{tabular}

Abbreviations: CRP, C-reactive protein; DIC, disseminated intravascular coagulation; DM, diabetes mellitus; FEU, fibrinogen equivalent units; HCQ, hydroxychloroquine; HD, hospital day.; HTN, hypertension; ISTH, International Society on Thrombosis and Haemostasis scoring system for DIC includes platelet count, D-dimer level, prothrombin time in seconds, and fibrinogen level ( $\geq 5$ points classifies as overt DIC); IVIG, intravenous immunoglobulin; LDH, lactate dehydrogenase; LMWH, low molecular weight heparin; MCA, middle cerebral artery; PT/INR, prothrombin time/international normalized ratio.

were routinely measured in all cases, with the sharpest derangements observed for D-dimer, followed by ferritin and PT/INR. Notable derangements in coagulation profile were found after a median duration of 7.5 days. Case 4 exhibited the highest level of ferritin and CRP and deteriorated rapidly. Predicted fatal outcomes have been reported in occurrence with high levels of D-dimer, and FDP further validating the use of these parameters as a risk stratification tool. ${ }^{9,10}$

In conclusion, at our facility, at the time of writing this report, four patients had fatal outcomes after developing COVID-19-associated DIC (of 28 COVID-19 patients admitted in our facility at the time). Hence, DIC in COVID-19 is a difficult complication to manage, and has a direct relationship to critical clinical status, leading to poor outcomes and may be considered as a poor prognostic indicator.

Conflict of Interest

None declared.

\section{References}

1 Klok F, Kruip MJHA, van der Meer NJM, et al. . Incidence of thrombotic complications in critically ill ICU patients with COVID-19. Thromb Res 2020;191:145-147 


\section{Fatal Disseminated Intravascular Coagulopathy in Covid-19 Kazmi et al.}

2 Thomas W, Varley J, Johnston A, et al. . Thrombotic complications of patients admitted to intensive care with COVID-19 at a teaching hospital in the United Kingdom. Thromb Res 2020;191:76-77

3 Middeldorp S, Coppens M, van Haaps TF, et al. . Incidence of venous thromboembolism in hospitalized patients with COVID19. J Thromb Haemost 2020

4 Helms J, Tacquard C, Severac FCRICS TRIGGERSEP Group (Clinical Research in Intensive Care and Sepsis Trial Group for Global Evaluation and Research in Sepsis)., et al; . High risk of thrombosis in patients with severe SARS-CoV-2 infection: a multicenter prospective cohort study. Intensive Care Med 2020;46(06):1089-1098

5 Cui S, Chen S, Li X, Liu S, Wang F. Prevalence of venous thromboembolism in patients with severe novel coronavirus pneumonia.J Thromb Haemost 2020;18(06):1421-1424

6 Lodigiani C, Iapichino G, Carenzo L, et al. . Venous and arterial thromboembolic complications in COVID-19 patients admitted to an academic hospital in Milan, Italy. Thromb Res 2020;191:9-14
7 Lippi G, Favaloro EJ. D-dimer is associated with severity of coronavirus disease 2019: a pooled analysis. Thromb Haemost 2020;120(05):876-878

8 Bikdeli B, Madhavan MV, Jimenez DGlobal COVID-19 Thrombosis Collaborative Group, Endorsed by the ISTH, NATF, ESVM, and the IUA, Supported by the ESC Working Group on Pulmonary Circulation and Right Ventricular Function. , et al; . COVID-19 and thrombotic or thromboembolic disease: implications for prevention, antithrombotic therapy, and follow-up: JACC stateof-the-art review. J Am Coll Cardiol 2020;75(23):2950-2973

9 Tang N, Li D, Wang X, Sun Z. Abnormal coagulation parameters are associated with poor prognosis in patients with novel coronavirus pneumonia. J Thromb Haemost 2020;18(04):844-847

10 Zhou F, Yu T, Du R, et al. . Clinical course and risk factors for mortality of adult inpatients with COVID-19 in Wuhan, China: a retrospective cohort study. Lancet 2020;395 (10229):1054-1062 